\title{
Crónica de una incursión etnográfica a la práctica docente en el bachillerato
}

\section{Chronicle of a high school class: An ethnographic approach}

\section{JuAn AndrÉS ELÍAS HERnÁndEZ*}

Las ideas y creencias que subyacen a la práctica docente en el nivel medio superior son el problema central de este documento, cuya característica principal es su adscripción al género narrativo en cruce con la investigación cualitativa; para ello se utiliza el recurso de la crónica. El estudio se desarrolló mediante una estrategia etnográfica de corte crítico y con un enfoque cualitativo, y se centró en la práctica docente de una maestra de bachillerato público, para lo cual se usaron las técnicas de observación participante y entrevista en profundidad. Los resultados muestran algunos posicionamientos epistemológicos, sociológicos, psicoeducativos y pedagógicos que caracterizan la práctica docente, además de condicionantes de orden contextual que atraviesan su actuar. Finalmente, se concluye en la necesidad de que el docente tome conciencia de las ideas y creencias que le subyacen, y asuma un mayor control sobre las decisiones didáctico-pedagógicas en su ámbito de gestión.

The ideas and beliefs that underlie teaching practice at the high school level are the central problem of this document, whose main characteristic is its ascription to the narrative genre articulate with qualitative research, using for that the resource of the chronicle. An ethnographic strategy with a critical paradigm and under a qualitative approach was carried out to study the teaching practice of a public high school teacher, using participant observation techniques and in-depth interviews. Through the study can be inferred some of the epistemological, sociological, psychoeducational, and pedagogical positions that characterize her teaching practice; as well as contextual conditions that influence her performance. Finally, it is concluded in the need for teachers to become aware of the ideas and beliefs that underlie them, and to assume greater control over didacticpedagogical decisions in their ambit of management.

\author{
Palabras clave: \\ creencias educativas, \\ práctica docente, \\ educación media \\ superior
}

\section{Keywords:}

educational beliefs, teaching practice, high school education

Recibido: 27 de febrero de 2018. | Aceptado para su publicación: 24 de julio de 2018. Recuperado de: https://sinectica.iteso.mx/index.php/SINECTICA/article/view/859 DOI: 10.31391/S2007-7033(2018)0051-004

\footnotetext{
* Maestro en Investigación Educativa Aplicada por la Universidad Autónoma de Ciudad Juárez (UACJ). Alterna la docencia y la investigación para el programa de la licenciatura en Educación de la UACJ, y en el Centro Chihuahuense de Estudios de Posgrado en las maestrías en Desarrollo Educativo y Competencias para la docencia. Se ha especializado en formación, acompañamiento y evaluación de docentes de distintos niveles educativos: básica, media superior y superior, y en aspectos del fenómeno educativo: análisis multirreferencial de la práctica docente, diseño curricular, planificación educativa, estrategias didácticas, procesos de evaluación de aprendizajes, diseño de materiales didácticos y habilidades docentes. Sus líneas de generación y aplicación del conocimiento son los procesos de enseñanza y aprendizajes, sujetos de la educación y modelos de gestión educativa.
} 
Resulta evidente que, en gran medida, lo que los docentes hacen es consecuencia de lo que piensan. Por otra parte, toda innovación en el contexto, las prácticas y la tecnología de la enseñanza estará forzosamente influida por la mentalidad y las motivaciones de los docentes. En la medida en que es "irreflexiva", la conducta observada en el docente o planeada por él no utiliza los atributos más singulares del enseñante humano. En tal caso, se vuelve mecánica y bien podría llevarse a cabo mediante una máquina.

Lee S. Shulman (1975, citado en Clark y Peterson, 1997, p. 445)

\section{INTRODUCCIÓN}

$\mathrm{E}$ ste documento se desprende de una investigación cuyo objetivo fue construir un mayor entendimiento de la práctica docente en el nivel medio superior a partir del análisis de las ideas y creencias educativas que le subyacen. Como producto de una inmersión etnográfica en el fenómeno educativo en cuestión, consideramos necesario comunicar parte de los resultados mediante formas que permitieran al lector encarnar las ideas en sujetos concretos, que no despojaran de humanidad a quienes participaron en el proceso, y que facilitaran pensar el fenómeno desde otra perspectiva, por lo que apelamos al giro narrativo y a la búsqueda de nuevas maneras de interpretación crítica (Denzin y Lincoln, 2011). Elegimos la crónica como la apuesta narrativa y a una docente de bachillerato púbico como el sujeto central de una discusión, que trasciende la individualidad y nos muestra de forma hologramática a toda una colectividad a través de ella.

La práctica docente en el bachillerato se debate entre el currículo formal, de aspiraciones constructivistas y con pretensiones de integralidad, y las condiciones organizativas, administrativas, socioculturales y contextuales de los diversos planteles, que difícilmente hacen viable la utopía educativa; esta contradicción constituye el argumento central de este documento cuyos esfuerzos se centran en visibilizar algunas de las tensiones cotidianas de la educación media superior en el sector público.

La estructura del artículo consiste en tres apartados. El primero, de carácter introductorio, caracteriza el objeto de estudio, así como la estrategia de indagación utilizada; presenta un breve esbozo de investigaciones previas que ofrecieron pautas para este ejercicio, y establece las orientaciones metodológicas que se siguieron. El segundo se basa en los resultados de investigación en la forma de crónica, cuyo personaje central es una docente participante de quien se comparten elementos biográficos, vocacionales y de incorporación al magisterio, como preámbulo para el abordaje de una experiencia de clase escolar que da cuenta de las condiciones en las que se ejerce la docencia en el bachillerato público. Por último, el tercer apartado comparte las conclusiones en cuanto a las características de la docencia observada desde una perspectiva multirreferencial (Ardoino, 1988), así como las tensiones, contradicciones y avatares que los sujetos de la educación media superior enfrentan.

La investigación utilizó una estrategia de corte etnográfico para introducirse en una escuela preparatoria pública con objeto de coadyuvar en la comprensión de la práctica docente, sin sustraerla del contexto que le da vida y de la cultura en la que cobra forma. Este ejercicio implicó realizar entrevistas y observaciones en el contexto escolar, y discusión de los resultados con la docente participante entre 2013 y 2016.

Elías Hernández. Crónica de una incursión etnográfica a la práctica docente en el bachillerato

Sinéctica 51 www.sinectica.iteso.mx 
La institución educativa en la que realizamos esta investigación se localiza en un sector de clase media en Ciudad Juárez, Chihuahua; sin embargo, la población estudiantil que asiste a ella es de distintos estratos sociales y proveniente de varias comunidades de la ciudad, que en términos gruesos van de clase baja a clase media. Esta condición, aunada a la diversidad cultural propia de la ciudad, que históricamente ha recibido a migrantes de todo el país por su posición geográfica y estratégica, deviene en un mosaico cultural multicolor que enriquece la vida escolar, pero que, a su vez, ofrece retos para la atención a la diversidad.

El plantel se caracteriza por contar con una planta docente joven que participa de manera activa en los procesos de formación al interior del subsistema y en las estrategias emanadas de la autoridad federal; persiste un modelo educativo tradicional y una dinámica administrativa que destaca los aspectos disciplinarios y deriva en una atmósfera restrictiva tanto del comportamiento del estudiantado como del actuar de los profesores.

Las ideas y creencias educativas, uno de los aspectos centrales del ejercicio, fueron discutidas mediante distintos prismas que permitieron esbozar un panorama amplio y complejo del objeto de estudio; para ello, utilizamos la propuesta de Ortega y Gasset (1940), que distingue entre ideas y creencias. Para este autor, las ideas representan constructos mentales fruto de nuestro trabajo intelectual, que se distinguen por ser maleables e incluso permutables; las creencias, en cambio, poseen un alto grado de implicación y suelen pasar inadvertidas, al confundirse con la realidad y, por tanto, condicionar nuestra percepción y actuar cotidiano. Las perspectivas disciplinarias utilizadas para el estudio de las ideas - explícitas y conscientes- y de las creencias -implícitas e inconscientes - que los docentes manifestaron en su discurso y en su práctica áulica fueron la epistemológica, la sociológica, la psicoeducativa y la pedagógica, todas observadas histórica y contextualmente.

El estudio de las ideas y creencias que subyacen a la práctica docente, su articulación al interior del sistema de creencias del profesor, y hacia el contexto escolar, del que se nutren, y en el que inciden, se ha realizado desde diversas perspectivas teóricas. De acuerdo con Pérez, Mateos, Scheuer y Martín (2006), los principales estudios en torno a las concepciones o creencias sobre los procesos de aprendizaje y enseñanza se pueden agrupar en seis enfoques: metacognición, teoría de la mente, creencias epistemológicas, fenomenografía, teorías implícitas, y perfil del docente y análisis de la práctica.

En nuestra investigación fueron relevantes en especial algunas investigaciones que indagan sobre las concepciones educativas de docentes y la forma en que estos constructos se articulan con la práctica y el contexto escolar: desde el referente disciplinario de la epistemología, Leal-Soto (2010), Müller, Rebmann, y Liebsch (2008) y Rebollo (2011); en el campo de la sociología de la educación, los estudios de Loubet-Orozco (2013) y Loubet-Orozco y Jacobo-García (2013); en el campo de la psicología educativa, Sales, Traver, Moliner y Doménech (2008) y Velasco, García y Linares (2012); y desde la investigación pedagógica, Estévez-Nenninger, ValdésCuervo, Arreola-Olivarría y Zavala-Escalante (2014) y Fernández, Pérez, Peña y Mercado (2011). Estos estudios concluyen en la necesidad de explorar las concepciones educativas como antesala del cambio en las prácticas docentes, pero difieren en el potencial de estos constructos mentales para la dirección y el control de la acción 
práctica; esto deviene en la necesidad de aportar a la comprensión de este objeto de estudio desde miradas multirreferenciales, sociohistóricas y contextualizadas, objetivo de la investigación de la que proviene esta aportación.

Para alcanzar el propósito planteado, optamos por el paradigma Crítico y otros, esbozado por Guba y Lincoln (2002); sin embargo, coincidimos con McLaren y Kincheloe (2008), que proponen la idea de un criticismo en evolución, nunca estático, siempre evolucionando a partir de nuevas perspectivas teóricas y de las aportaciones de los diversos pueblos y culturas. En esencia, este paradigma es antidogmático, al plantear que los conocimientos que se crean están permanentemente sometidos a la duda y pueden comprenderse solo en el marco de un contexto sociohistórico. La propuesta paradigmática pretende que, sin menoscabo de las construcciones intelectuales, sea accesible a los diversos interesados e involucrados en el problema de investigación, y que más que transformar a los individuos, favorezca que el propio sujeto sea dueño y artífice de su propia transformación.

Asimismo, utilizamos una metodología cualitativa, definida por Denzin y Lincoln (1994) como "un proceso multicultural y de géneros. [...] [un] campo de indagación por derecho propio, [que] entrecruza disciplinas, campos y problemáticas" (p. 1); esto, en atención a un objeto de estudio, en esencia subjetivo, que reacciona ante la observación, un objeto peculiar, complejo e impredecible (McLaren y Kincheloe, 2008), en ocasiones irracional, errático y emocional, capaz de deshacer y desarmar las estrategias que intentan conocerlo (Ardoino, 1988) y que es, en términos llanos, escurridizo.

En complementariedad, trabajamos desde un enfoque etnográfico con las técnicas de observación participante y entrevista en profundidad. La estrategia etnográfica busca develar estructuras de significados, comprender una cultura a través de descripciones complejas y amplias que permiten interpretar una realidad (Ameigeiras, 2007). Esta estrategia requiere de modo necesario "andar el camino" y, en específico para esta investigación, ser parte de la comunidad a la que no se estudia, sino de la que se aprende; vivir su cotidianidad, escuchar lo que dicen, ver e interactuar, comprender y construir una realidad desde la perspectiva de sus protagonistas (Guber, 2001).

Comprender las ideas y las creencias que subyacen a la práctica docente, y la manera en que se articulan con el contexto interno y externo del plantel escolar donde se manifiestan, implica un arduo y reflexivo proceso - individual y colegiado- de análisis, que transita entre la observación y el diálogo. Ambas técnicas, en complementariedad, permiten observar manifestaciones empíricas desde perspectivas diversas que serán después confrontadas mediante el diálogo, con objeto de construir un saber colectivo. Observar sin dialogar nos coloca frente al riesgo de construir una visión parcial, limitada, y posiblemente errada; dialogar sin observar acota el análisis al terreno del discurso; ambas técnicas acercan al investigador a una realidad intersubjetiva que otorga validez/credibilidad/confianza sobre el proceso y los resultados del estudio (Mendizábal, 2007).

Un último apunte metodológico que sitúa nuestro documento es su aspiración a contribuir a las líneas de generación de conocimiento que exploran formas distintas de construcción de saberes y difusión de resultados de investigación, como la etnografía performativa, la autoetnografía, la representación poética y diversos 
géneros narrativos, en este caso la crónica. En esas líneas de trabajo, ubicadas en la alteridad con relación a la investigación tradicional y hegemónica, se exploran formas alternativas de escritura que puedan construir puentes comunicativos entre comunidades de investigación y aprendizaje, donde las posiciones tradicionales de investigador-investigado se problematicen y transformen; donde se busquen procesos y productos que trasciendan la racionalidad en el entendimiento de realidades complejas; que articulen lo personal con lo político, lo biográfico con lo histórico (Denzin, 2017), y lo individual con lo social en un discurso encarnado.

La crónica presentada a continuación fue construida a través de las diversas entrevistas con la docente participante, de la observación directa en clase, y de la discusión de resultados desarrollada desde una perspectiva dialógica entre el investigador y la participante, concebida no solo como una informante clave, sino como co-investigadora. Desde el posicionamiento paradigmático y metodológico asumido, consideramos necesario mostrar los resultados en esta forma narrativa con objeto de alcanzar una comunicación holística y orgánica de un fenómeno irreductible a sus componentes particulares.

\section{LA CRÓNICA}

Lejos estaba de su ciudad de origen, aquella que por pequeña era grande, pese a la carga cultural que le imponía, carga que en ocasiones era aplastante, casi asfixiante, y en otras, ligera, tanto como aceptara su condición de mujer:

Maestra: Vengo de una población arraigada todavía a las tradiciones de una ciudad pequeña, donde las mujeres, única y exclusivamente tenemos derecho hasta cierto límite de estudios; a mí se me inculcó en la casa que yo no debía estudiar más allá de la secundaria o la preparatoria, porque son cuestiones de mala inversión, si te vas a casar, ¿para qué estudiar? [...]. Mi primera inquietud fue estudiar aviación, otro impedimento que me dijo, tanto la sociedad como la familia; hay [posibilidades de formación] para aeromoza o sobrecargo, pero habría que estudiar fuera y por cuestiones económicas me dijeron que no; [...] recurro a dependencias gubernamentales, igual me dicen no. Mujeres no se admiten en la fuerza aérea y el gobierno no tiene esa facultad para darte esos estudios, y yo pregunto, bueno..., pero, ¿por qué?, dime, eres muy chaparra, eres gordita, tu nivel intelectual no es suficiente, porque no aprobaste un examen de aptitudes, o no aprobaste ciertas cualidades, iy no!, simplemente se cierran las puertas. [...] En la familia fuimos dos hermanos, el menor varón sí fue apoyado para estudiar una carrera. A él sí se le dieron otras facilidades [...] por ser el que iba a proveer a una familia (entrevista personal).

Los vericuetos de la vida $-y$ su sueño por estudiar una carrera universitaria- la llevaron a la docencia, que a fuerza de respirarse impregnó su vida y la hizo descubrir que lo único que quería para el resto de su vida era enseñar; sentir el bochorno cotidiano de las precarias aulas públicas, pasar media vida en las penumbras que dejó la continua ausencia de iluminación y presupuesto para infraestructura, sumergirse en el denso respirar de sesenta jóvenes de bachillerato que irradian vida por sus ojos, y sudores por sus cuerpos; ser maestra, aun cuando esto implique cumplir a cabalidad la agenda político-educativa que le señalen sus directivos, y "tragar sin hacer gestos".

Su sentir particular se puede percibir en las distintas experiencias formativas y de investigación en el estado de Chihuahua; a través de ellas se recogen impresiones de docentes de bachillerato público que comparten la conclusión a la que llega Guzmán (2005): 
Como vemos, en ningún caso, desde esta perspectiva, puede considerarse al docente como un profesional autónomo que toma decisiones pedagógicas Así, pedirle al profesor que colabore en la reforma para lograr la calidad educativa resulta contradictorio cuando en realidad lo que se les pide es que se comprometan con una visión que los concibe como sujetos pasivos, sumisos, obedientes: buenos técnicos que aplican lo que proponen los expertos (p. 6).

Al enfrentarse a la desafiante tarea de enseñar, la maestra miraba a su pasado buscando entre sus memorias pautas para orientar su actuar docente. Estudiante destacada no había sido, "no era una persona muy centrada en los libros, era más bien inquieta y con un toque de suerte, lo poco que lograba captar cuando entraba [a clases], venía en el examen" (entrevista personal); en secundaria gustaba algunas veces de escabullirse por la reja de la escuela para ocuparse en cosas de mayor trascendencia, como divertirse en juegos de mesa o videojuegos.

Recordemos que, históricamente, los puestos docentes en el nivel medio superior han sido ocupados por profesionales de distintas disciplinas sin formación inicial didáctico-pedagógica, por lo que prima su experiencia profesional y formación disciplinaria (Alcántara y Zorrilla, 2010), de ahí que su bagaje académico (fase preformativa) resulte fundamental al momento de tomar decisiones para orientar su enseñanza.

Entre las memorias que la dotaban de recursos para la enseñanza, se encontraba el recuerdo de un maestro de preparatoria que le impartía la clase de filosofía; aquel sabio y buen hombre le había despertado el interés por los libros, trastocando su alma a grado tal que permaneció en su mente no obstante el paso del tiempo; con él terminó de construir una creencia: el docente es una persona que sabe. Otro recuerdo indeleble lo tenía de su maestro de Dibujo técnico, un hombre de edad avanzada -al parecer ingeniero-, que en su clase les daba la libertad, incluso de irse; quien decidiera quedarse tendría como recompensa escuchar maravillosas historias mientras dibujaba en su restirador, armado con una regla T, lápices y paciencia. De este maestro, incorporaría la cercanía en la relación docente-alumno, la cotidianidad impregnando la escuela, y la necesidad de respirar un ambiente de libertad en el aula.

Estas experiencias, bebidas lenta y paulatinamente, constituyen el subsuelo sobre el que se yergue la arquitectura de un docente, hacer conciencia de estas creencias es, para distintos investigadores, un paso imprescindible para la transformación docente; vía ya resuelta por Ortega y Gasset en 1940:

¿Se entrevé ya el enorme error cometido al querer aclarar la vida de un hombre o una época por su ideario; esto es, por sus pensamientos especiales, en lugar de penetrar más hondo, hasta el estrato de sus creencias más o menos inexpresas, de las cosas con que contaba? Hacer esto, fijar el inventario de las cosas con que se cuenta, sería, de verdad, construir la historia, esclarecer la vida desde su subsuelo (pp. 24-25).

Esa mañana, con todo lo anterior a cuestas, se dirigió a impartir su clase; sin embargo, antes de entrar al salón, tuvo que pasar a la oficina del subdirector por un embrollo académico; había osado reprobar a una "ejemplar" estudiante y estaba siendo llamada a cuentas tras la ofuscada intervención del padre de familia, quien lejos de solicitar a su hija que asumiera las consecuencias de sus actos -la estudiante había incumplido un acuerdo-, la disculpó al afirmar que "ella estaba muy chica para tomar esas responsabilidades" (entrevista personal). El mito socialmente construido de la incapacidad de discernimiento del adolescente se hacía presente, esa mentira 
que a fuerza de pronunciarse en tantas ocasiones cobró valor real; en fin, asumió la institucionalidad y reviró tratando de conservar la mayor dignidad posible.

La asignatura que impartía buscaba favorecer los aprendizajes relacionados con el autoconocimiento, el respeto hacia las demás formas de pensar, la democracia, los derechos humanos, entre otros temas; en suma, los estudiantes -en el discurso- analizaban "las diversas formas de pensar, culturales y morales, y cómo han evolucionado, para crear una propia [forma de pensar], pero así mismo reflexionar sobre las demás y tomar un conciencia crítica" (entrevista personal). Sin embargo, estos aprendizajes, en algunos casos y de acuerdo con la maestra, permanecían como meras aspiraciones ante la avalancha de obstáculos que se le ofrecían, como la constitución de grupos numerosos de alumnos, saturación de contenidos curriculares, constantes interrupciones por cuestiones políticas, burocráticas, o simplemente extraacadémicas; el deterioro e inadecuación de la infraestructura y mobiliario escolar; los problemas propios del estudiante, sobre todo su deficiente habilidad y ausente propensión para el estudio y su dependencia a las redes sociales a través de aparatos telefónicos:

Maestra: El estudiante es un producto de las competencias, entonces, como producto sin terminar de las competencias no se afianzó, ni la competencia ni el modelo anterior. Entonces están en un punto en el que si los pongo a trabajar en equipo no trabajan, pero si los pongo a trabajar al modelo antiguo de aprender de memoria, escribir o dictado, ¡tampoco! se resisten, no traen ni un modelo ni otro (entrevista personal).

El aula asignada a la maestra medía casi siete metros de ancho por nueve metros de largo, sobrepintada en su undécima ocasión en tono beige, con un espacio prominente al frente para el docente de aproximadamente 30 centímetros de altura y 1.5 metros de ancho. En el aula había alrededor de 60 pupitres enteramente ocupados por un grupo de estudiantes, hombres y mujeres en proporciones similares. La distancia entre filas era de unos 40 centímetros, mientras que entre pupitres era nula. Solo una de las paredes tenía ventanas, las cuales miraban a un patio abandonado que daba la apariencia de una ciudad fantasma.

Los estudiantes se fueron integrando de manera paulatina, con la tranquilidad que brinda la sana inocencia de ignorar el momento histórico, en el que la educación sucumbe al neoliberalismo más salvaje y mimético de la historia, inaugurado de manera formal en nuestro país en 1992, año en que se firmó el Acuerdo Nacional para la Modernización de la Educación Básica. A partir de este acto, se ha ido acelerando la consolidación de una escuela al servicio de un régimen neoliberal (Zorrilla y Barba, 2008, p. 14); hemos sido testigos de una oleada de reformas que se fundamentan en el enfoque por competencias, con el auspicio de un "Estado evaluador" al servicio de intereses económicos.

Una tendencia a la privatización de la educación, en concordancia con ese Estado distinto, pero no ausente (Vassiliades, 2008), cimentada en una campaña mediática, han terminado por desdibujar al ya debilitado Sindicato Nacional de Trabajadores de la Educación y a otras tantas agrupaciones de docentes. Los años venideros vislumbran un escenario caótico, que, de no cambiar la política educativa, coronarán al régimen neoliberal sobre las ruinas de la anquilosada y retrograda escuela mexicana. 
Las primeras palabras de la docente fueron: “iLibro y cuaderno, [...] saquen libro y cuaderno!", consigna que como campana pavloviana situó a la clase en otra sintonía, y dejó un halo de ansiedad y prisa en la atmósfera preparatoriana. Nosotros observábamos y la primera sensación que tuvimos al mirar la práctica de la docente fue de urgencia; dicha impresión se reforzaría al continuar la clase. Nos preguntamos ¿cuál era la prioridad dictada a la maestra?, ¿terminar con el llenado del libro?, ¿a qué se debía esto? Con voz segura y fuerte, ella les dio las indicaciones. Había que encontrar cinco definiciones de democracia, una de ellas de su libro de texto, un libro como de dos pulgadas y media, que no solo pesa, sino que es complicado consultar en los pequeños pupitres del aula, lo que hacía de esto no solo una actividad para desarrollar habilidades cognitivas inferiores, sino de motricidad y equilibrio. El resto de las definiciones provendrían de otros textos. Por último, una vez anotada cada una de las acepciones, era necesario presentar la bibliografía de la que fueron tomadas:

Maestra: Si, para el maestro hay llamadas de atención, de hecho nos están revisando la evolución en los temas, nosotros tenemos tarjetones que es necesario llenar a diario para ver qué temas hemos visto, y una calendarización por temas, entonces a nosotros nos están revisando que a determinada fecha tengamos un avance programático ya cubierto, igual revisan evidencias de los jóvenes, yo tengo que entregar un cuaderno y entregar trabajos de acuerdo también con mis tarjetones. Si en mis tarjetones dicen que yo el lunes vi ecología y medio ambiente, yo tengo que dejar evidencia de que ese día, di ecología y medio ambiente [...]. Ya tenemos identificados a los jóvenes, y créame que yo lo hago, al mejor cuaderno, más entendible, con fechas, al alumno que escribe fecha, que escribe legible, que tiene el cuaderno limpio, que tiene el cuaderno completo, es al alumno que yo se lo pido y lo dejo ahí, dejo el libro y dejo el cuaderno, y dejo los trabajos que avalen los temas que vimos (entrevista personal).

Cobra cruda relevancia la máxima de Birnbaum (2001), si no podemos medir lo que es valioso, acabaremos valorando nada más lo que es medible y enfocando nuestros esfuerzos en cuestiones nimias en menoscabo de lo realmente trascendente del acto educativo.

Con la misma sensación de urgencia, la maestra sacó de unos anaqueles grises y deteriorados situados en una esquina del salón libros para consultar las definiciones y empezó a repartirlos a diestra y siniestra entre los estudiantes, en un orden de derecha a izquierda del salón; cuando llegó a las últimas filas (lado izquierdo), ya no tenía libros suficientes y dejó apenas unos cuantos. Un estudiante exclamó que ellos no tenían libro, pero no hubo respuesta de la docente; en cambio, una de sus compañeras sí le respondió: "Allá cada quien tiene su libro (derecha), nosotros no". Las palabras de la estudiante estaban cargadas de decepción; el mensaje implícito era de reproche hacia la docente por su falta de atención igualitaria a todos los estudiantes, por volcar su esfuerzo hacia una parte del grupo (derecha), y olvidar a la otra (izquierda). Entonces, en el proceso de observación surgieron muchas preguntas: ¿en qué medida el interés mostrado por la docente hacia sus estudiantes les motiva -o desmotiva- a afrontar la tarea de aprender?, ¿cómo realizar nuestra tarea docente ante tales condiciones y limitaciones?, ¿cómo permitimos que adelgazaran el concepto de calidad educativa a unos cuantos indicadores de salida? Tras las preguntas llegaron sentimientos de rabia e impotencia que encontraron su cenit en un suspiro.

Como mencionamos, el salón estaba ocupado por alrededor de sesenta estudiantes; la docente trataba de acercarse a ellos para dar indicaciones personalizadas, pero le era prácticamente imposible; sus consignas llegaban tan solo a la mitad del 
grupo; de hecho, su atención -y su mirada- se centraban en sus estudiantes de la derecha. Un equipo situado en la parte izquierda trasera, conformado por hombres, tenía su propia temática de discusión, platicaban del fin de semana y de sus amigas, mientras la clase transcurría; pasarían veinte minutos hasta que el primero de ellos intentara unirse a la actividad de clase; al percatarse la maestra de que este subgrupo no estaba trabajando, empezó a disolverlos cambiándolos de lugar; les indicaba dónde sentarse mientras les canturreaba: “Corre conejo, corre veloz!”.

Las dudas eran aclaradas, en su mayoría, por los mismos estudiantes, quienes se compartían las instrucciones en un despliegue forzado, y tal vez inconsciente, de trabajo solidario, no sin antes tergiversar las ideas un poco en una suerte de "teléfono descompuesto"; un alumno preguntó si sacarían las definiciones de Wikipedia, mientras otro, con voz hinchada, con esa solemnidad que da la certeza absoluta e ingenua, le respondió: "Dicen que Wikipedia es mentira”. El interrogador estoicamente asiente. Cabe hacer una breve pausa en el desprestigio de Wikipedia no circunscrito a la preparatoria; en los círculos académicos resulta inaceptable consultar esta fuente, no obstante sería interesante cuestionarse a qué se debe esto, si es solo por la duda razonable de su veracidad o atiende a cuestiones distintas de naturaleza económica o academicista (Casebourne, Davies, Fernandes y Norman, 2012); sea cual fuera la respuesta, es parte del discurso del que se están apropiando los estudiantes.

La maestra, en la medida de sus posibilidades, se acercó a sus estudiantes, mientras los instaba a apurarse, "si no, no acaban", por lo que continuamente les preguntaba “¿ya merito?” La tarea se desarrollaba de manera mecánica, los jóvenes transcribían, mientras platicaban de sus asuntos personales, tal vez más importantes. Ni siquiera buscaban las definiciones, la docente les daba las páginas para terminar con la actividad a tiempo.

Conforme avanzaban los minutos, la presión aumentaba. La maestra consultaba su reloj con mayor frecuencia, les pedía rapidez, les preguntaba si ya habían cambiado de libro, o cuántas definiciones llevaban. Su prisa les fue transmitida a sus estudiantes, quienes, con desesperación, empezaron a moverse de ubicación para transcribir definiciones de otros libros, pero el mobiliario impedía el trabajo en pequeños grupos.

La docente miró el reloj; faltaban doce minutos para el timbre; entonces, empezó a recoger libros al mismo tiempo que les indicaba que las definiciones tenían que estar igualitas, esto es, copiadas textualmente. Los más rápidos le llevaron sus cinco definiciones a revisión, y ella les preguntó “¿y la suya?” Los alumnos le respondieron “¿cuál?”. Les comentó que tenían que haber transcrito cinco definiciones, y construir una propia, ahora serían seis. Los jóvenes regresaron apurados a sus pupitres a redactar su definición. No cuestionaron, ya que asumen que fue su error.

Empezaron a formarse para revisar, mientras la maestra leía con rapidez lo hecho por los estudiantes y sellaba "de recibido" el trabajo con una destreza sobresaliente. Conforme fueron atiborrándose los estudiantes, la revisión de la docente bajó de rigor, y tan solo verificaba que hubiera seis enunciados, sin dar lectura cabal a estos. Cuando fenecía la clase, la exigencia bajó a cuatro definiciones y la propia, tratando de ayudar a quien no había concluido. Un alumno que a lo mucho había copiado dos definiciones, solicitaba ansioso los cuadernos de sus compañeros para 
transcribir de manera rápida las otras definiciones; su breve esfuerzo se vería recompensado con un sello, testigo inapelable de que la faena había sido cumplida. ¿Qué valor tenían los sellos en la dinámica del aula?, ¿por qué la docente de manera religiosa los suministraba, y los estudiantes los buscaban de forma frenética?, ¿pueden representar un mecanismo de evaluación formativa o formadora?, ¿favorecen el aprendizaje?“¡Vámonos!, ¡terminó la clase! ¡No se vayan a llevar mis libros!”, exclamaba como cierre la docente. La clase acabó como empezó, y así fue como estos estudiantes "se aproximaron" al concepto de democracia.

\section{ConCluSión}

¿Qué se puede decir de la práctica descrita desde una mirada multirreferencial de la docencia? Desde la perspectiva epistemológica, la docente se debate entre un posicionamiento dogmático y uno escéptico (Elías, 2016). Para algunos estudiantes el acto cognoscente fue la simple asimilación de un concepto (realismo-empirismo), y para otros, la posibilidad de realizar una construcción subjetiva, fundada en el idealismo y el racionalismo. Sociológicamente se presenta en forma estructural-funcionalista, en razón de que el cuestionamiento del término "democracia" y sus implicaciones individuales y colectivas están ausentes. En términos psicoeducativos, las estrategias propuestas son, en su mayoría, de orden conductual, lo cual no se ajusta por completo a su incipiente constructivismo epistemológico, es decir, las actividades son ante todo de repetición y asimilación de contenidos con una limitada aspiración a la construcción de aprendizajes. Por último, desde la perspectiva pedagógica, se evidencia un enfoque ejecutivo (Fenstermacher y Soltis, 2007), en el cual el foco de interés de la docente se sitúa solo en el aprendizaje de contenidos, por lo regular declarativos o procedimentales. El desarrollo personal, cognitivo, crítico-reflexivo y humano no fue abordado en forma intencionada ni explícita, al menos en la sesión de trabajo descrita, aspecto que se complementa con su discurso, en el cual la docente sí manifiesta un interés por trascender el enfoque ejecutivo de la enseñanza:

Maestra: Como se lo hice saber a una jovencita [...], mi objetivo no es que tú aprobaras con diez; mi objetivo es que tú llevaras herramientas, no para la universidad, sino para la vida, que llevaras un conocimiento para enfrentarte ante una problemática, o ante alguna situación que se tuviera que resolver de acuerdo a un aprendizaje que vimos aquí, no creo haberles estado yo promoviendo aprendizaje para que pasaran un examen, para mí es lo más erróneo que puede haber (entrevista personal).

Lo anterior, sin embargo, resulta de mirar un "momento en el vacío" del fenómeno educativo; el actuar de la docente se encuentra mediado - y trasgredido- por aspectos administrativos y contextuales, aunado a las creencias e ideas que ostentan ella y sus propios estudiantes, las cuales no actúan de forma independiente, sino dialéctica.

La maestra no posee total control sobre el contenido curricular a desarrollar ni sobre los tiempos para abordarlo. Estos aspectos son auditados desde los órganos de control académico:

Maestra: Nuestras escuelas están ligadas a un sistema que viene determinado, los mapas curriculares, todo en base no tanto a lo mejor, en las necesidades, ni siquiera a las regiones específicas del país, sino que todavía seguimos siendo centralizados (entrevista personal). 
Por querer ver todos los temas los abarcamos superficialmente, entonces queda ya mucho a criterio del docente, cuáles temas toma a profundidad y cuáles no, a cuáles les da una mayor carga horaria y a cuáles no, o a cuáles tienes el tiempo de verlos. Ya cuando tenemos mucha suspensión [de clases] lo vemos, subrayamos y nos vamos (entrevista personal).

La propuesta didáctica, de igual modo, es atravesada por condicionantes como la sobrepoblación en el aula, lo cual lleva a la maestra a seleccionar las estrategias didácticas, no con base en el contenido a desarrollar, sino

las que me alcanza el tiempo [...] la clase es de cincuenta minutos, y yo tengo cincuenta y seis alumnos; si le dedico un minuto a cada alumno, de perdida para leer a grosso modo la reflexión de cada uno, me van a quedar seis bailando, o sea, matemáticamente no me cuadra (entrevista personal).

Otros obstáculos son el acceso a materiales y recursos didácticos, la temporalidad que obedece a criterios organizativos, más que pedagógicos y, sobre todo, la manera en que los estudiantes se enfrentan al proceso educativo, en su mayoría, buscando la facilidad y el menor esfuerzo, la inmediatez y el requerimiento compulsivo por ser dirigido y retroalimentado en todo momento, entre otras construcciones sociales.

Ante este panorama, la docente concluye que la escuela no se orienta a la formación integral de los estudiantes, y que poco o nada puede hacer para revertir el destino de sus alumnos, marcado por sus condiciones socioeconómicas y culturales. Esta convicción la lleva a una reflexión pragmática desde una perspectiva funcionalista: su labor consiste en dotar a sus estudiantes de los elementos que requerirán para incorporarse a la vida y al trabajo en el marco del único futuro posible para ellos, de lo que resulta su interés por desarrollar competencias para el trabajo y para la convivencia, ausente de conflicto y en los márgenes de la institucionalidad:

Maestra: Yo estoy haciendo a los jóvenes funcionales; funcionales y formativos exactamente para una sociedad, no de Finlandia, no de Estados Unidos, para esta, [para una sociedad en] donde la mayor parte va trabajar en la maquila, así de fácil, y te vas a apegar a reglas, a horarios, a dogmas, de que aquí así se trabaja, es una teoría de reproducción, pero en fin. [De lo contrario] estaría creando un modelo ideológico de una persona que va a ser infeliz y va estar inadaptada, pero en fin, qué caso tiene estarnos amargando (entrevista personal).

Es fundamental anotar que la sesión descrita, si bien nos brinda algunos elementos para entender la práctica de la maestra - en su contexto-, no representa la totalidad de su cátedra. A través de las sesiones de observación y el diálogo constante, fuimos testigos de las luchas internas de la docente por llevar a cabo una práctica tendente a la integralidad, desde la forma en que la concibe; un jaloneo conceptual entre lo que consideraba pertinente, los lineamientos administrativos que condicionan su trabajo, y el propio contexto social, escolar y de aula (Fenstermacher y Soltis, 2007). Sin embargo, y aquí radica la importancia del ejercicio, dicha sesión resulta sumamente ilustrativa de las condiciones en las que se ejerce la docencia en el bachillerato mexicano.

La educación media superior pública en México arrastra los lastres derivados de las políticas educativas y el "espíritu del tiempo". En el bachillerato coexisten la sobresaturación y descontextualización de los contenidos, la precariedad de recursos 
e infraestructura, una tensión entre un currículo formal de aspiraciones constructivistas y un modelo educativo arraigadamente tradicionalista, un indefinición sobre la finalidad del nivel, incrementada con la reciente iniciativa de obligatoriedad, y la presencia de procesos evaluativos que invitan a la simulación.

La perspectiva para este estudio consistió en contrastar de manera colegiada la práctica de la docente con sus ideas y creencias expresas e implícitas, contextualizadas e históricamente situadas; aspiramos a que, tras la observación y discusión, la docente tomara un mayor control de su praxis educativa. Aunado a esto, el proceso mismo constituyó un crisol en el que los participantes, principalmente el investigador titular, reconfiguraron su perspectiva del fenómeno estudiado y, sobre todo, su manera de observar-investigar:

Caminar esta senda me permitió vivir, sentir y respirar la problemática, dotándola en un suspiro, de alma y sangre; escuchar, crecer y compartir a través de la interacción de nuestros corazones, mentes y voces; dialogar con autores vivos y eternos, y cuestionar, diferir y asentir con sus constelaciones teóricas. Hoy, más que nunca, abrazo la idea de que el valor del andar no está en la ansiada llegada, sino en la belleza del camino andado (Elías, 2016, p. 117).

El estudio hizo posible "mirar" al interior del entramado histórico y contextual que conforma la práctica docente de una profesora de bachillerato, y a través de ese mirar, iniciar un diálogo con la participante a efectos de avanzar en la comprensión de las condiciones en las que se ejerce la docencia en este nivel educativo. Las limitaciones son diversas: el estudio se acotó a un subsistema educativo, un solo campo disciplinario, a semestres de nivel inicial, desde un acercamiento metodológico cualitativo, para este caso concreto con una sola docente, sin trascender a la intervención e, históricamente, previo a la introducción de una nueva reforma educativa que vuelve a tensar los hilos curriculares en el bachillerato. Cada una de estas limitantes ofrece rutas para el desarrollo de nuevas propuestas de investigación; sin embargo, coincidimos con Beuchat-Reichardt (2010) cuando plantea que

[en las reformas educativas latinoamericanas] se enmascaran nuevas y crecientes demandas al profesorado que se traducen en una creciente descalificación y proletarización del trabajo docente a través de la estandarización de competencias y habilidades de enseñanza y la división social del trabajo entre quienes piensan y quienes ejecutan (p. 52).

De ahí que se perciba la apremiante necesidad de formular propuestas articuladas de investigación y formación docente que favorezcan la construcción de comunidades autónomas de indagación y aprendizaje, y la autogestión por parte de los docentes de sus procesos de transformación, fundados en un profundo conocimiento de los sustentos teórico-conceptuales que dan sentido a su actividad profesional y una vinculación estrecha con la práctica cotidiana.

\section{REFERENCIAS BIBLIOGRÁFICAS}

Alcántara, A. y Zorrilla, J. (2010). Globalización y educación media superior en México. En busca de la pertinencia curricular. Perfiles Educativos, vol. XXXII, núm. 127, pp. 38-57. Recuperado de http://www.scielo.org.mx/pdf/peredu/ v32n127/v32n127a3.pdf

Ameigeiras, A. (2007). El abordaje etnográfico en la investigación social. En A. Vasilachis et al. Estrategias de investigación cualitativa (pp. 107-151). Buenos Aires, Argentina: Gedisa. 
Ardoino, J. (1988, noviembre). Lo multirreferencial en torno a los problemas de investigación. Recuperado de Universidad Autónoma Metropolitana, Unidad Xochimilco. División de Ciencias Sociales y Humanidades: http://csh.xoc. uam.mx/psicologiagrupos/Textos.pdf

Beuchat-Reichardt, M. (2010). Concepción de aprendizaje en estudiantes de pedagogía básica. Tesis doctoral. Recuperado de Universidad de Granada: http://hera.ugr.es/tesisugr/18747449.pdf

Birnbaum, R. (2001). Management Fads in Higher Education. San Francisco: Jossey-Bass.

Casebourne, I., Davies, C., Fernandes, M. y Norman, N. (2012). Evaluación de la exactitud y calidad de las entradas de Wikipedia en comparación con otras conocidas enciclopedias alternativas en línea: un estudio preliminar comparativo interdisciplinario en inglés, español y árabe. Recuperado de Wikimedia Commons: https://commons.wikimedia.org/wiki/File:EPIC_Oxford_report.pdf

Clark, C., y Peterson, P. (1997). Procesos de pensamiento de los docentes. En M. Wittrock. La investigación de la enseñanza, III. Profesores y alumnos (pp. 443539). Barcelona, España: Paidós.

Denzin, N. L. (2017). Autoetnografía Interpretativa. Investigacion Cualitati$v a$, vol. 2, núm. 1, pp. 81-90. Recuperado de https://ojs.revistainvestigacioncualitativa.com/index.php/ric/article/view/77/43

Denzin, N. y Lincoln, Y. (2011). Manual de investigación cualitativa (vol. I). Barcelona: Gedisa.

Denzin, N. y Lincoln, Y. (1994). Manual de investigación cualitativa (M. Perrone, trad.). California, EUA: Sage.

Elías, J. A. (2016). Compromisos e implicaciones que subyacen a la práctica docente en educación media superior. Una mirada desde la multirreferencialidad. Ciudad Juárez, Chihuahua, México: UACJ. Recuperado de http://erecursos. uacj.mx/handle/20.500.11961/3589

Estévez-Nenninger, E., Valdés-Cuervo, Á., Arreola-Olivarría, C. y Zavala-Escalante, M. (2014). Creencias sobre enseñanza y aprendizaje en docentes universitarios. Revista Internacional de Investigación en Educación, vol. 6, núm. 13, pp. 49-64. Recuperado de http://revistas.javeriana.edu.co/index.php/ MAGIS/article/view/8784

Fenstermacher, G. y Soltis, J. (2007). Enfoques de la enseñanza (A. Bixio, trad.) Buenos Aires, Argentina: Amorrortu.

Fernández, M., Pérez, R., Peña, S. y Mercado, S. (2011). Concepciones sobre la enseñanza del profesorado y sus actuaciones en clase de ciencias naturales de educación secundaria. Revista Mexicana de Investigación Educativa, vol. 16, núm. 49, pp. 571-596. Recuperado de http://www.scielo.org.mx/pdf/rmie/ v16n49/v16n49a11.pdf

Guba, E. y Lincoln, Y. (2002). Paradigmas en competencia en la investigación cualitativa. En C. Denman y J. Haro. Por los rincones. Antología de métodos cualitativos en la investigación social (pp. 113-145). Hermosillo, Sonora, México: El Colegio de Sonora.

Guber, R. (2001). La etnografía, método, campo y reflexividad. Bogotá: Grupo Editorial Norma.

Guzmán, C. (2005, septiembre). Reformas educativas en América Latina: un análisis crítico. Revista Iberoamericana de Educación, vol. 36, núm. 8, pp. 1-11. Recuperado de https://rieoei.org/RIE/article/view/2779 
Leal-Soto, F. (2010). Creencias epistemológicas generales, académicas y disciplinares en relación con el contexto. Universitas Psychologica, vol. 9, núm. 2, pp. 381-392. Recuperado de http://revistas.javeriana.edu.co/index.php/revPsycho/article/view/254

Loubet-Orozco, R. (2013). La reflexión del profesor de educación básica formado en la sociología. En J. Sancho, J. Correa, X. Giró y L. Fraga. Aprender a ser docente en un mundo en cambio (pp. 390-397). Barcelona: Dipòsit Digital de la Universitat de Barcelona.

Loubet-Orozco, R. y Jacobo-García, H. (2013). La reflexión sociofuncional y crítica de los profesores de programas de educación para la población infantil migrante. Revista Internacional de Educación para la Justicia Social, vol. 2, núm. 1, pp. 195-212. Recuperado de de htt://www.rinace.net/riejs/ numeros/vol2-num1/art10.pdf

McLaren, P. y Kincheloe, J. (2008). Pedagogía crítica. De qué hablamos, dónde estamos (M. Serrano, trad.). Barcelona, España: GRAO.

Mendizábal, N. (2007). Los componentes del diseño flexible en la investigación cualitativa. En A. Vasilachis et al. Estrategias de investigación cualitativa (pp. 65-105). Buenos Aires, Argentina: Gedisa.

Müller, S., Rebmann, K. y Liebsch, E. (2008). Las creencias de los formadores acerca del conocimiento y el aprendizaje: un estudio piloto. Revista Europea de Formación Profesional, vol. 45, núm. 3, pp. 99-119. Recuperado de http:// www.cedefop.europa.eu/files/45-es.pdf

Ortega y Gasset, J. (1940). Ideas y creencias. Argentina: Espasa-Calpe.

Pérez, M., Mateos, M., Scheuer, N. y Martín, E. (2006). Enfoques en el estudio de las concepciones sobre el aprendizaje y la enseñanza. En J. I. Pozo. Nuevas formas de pensar la enseñanza y el aprendizaje. Las concepciones de profesores y alumnos (pp. 55-94). Barcelona: Grao.

Rebollo, J. (2011, octubre). Concepciones epistemológicas de ciencia y techología en los profesores de bachillerato: un estudio empírico en el estado de Guanajuato. Recuperado del repositorio digital IPN: http://www.repositoriodigital. ipn.mx/handle/123456789/3005

Sales, A., Traver, J., Moliner, O. y Doménech, F. (2008). De las perspectivas docentes transmisivas y constructivas a la construcción compartida del conocimiento: satisfacción e implicación profesional del profesorado. Quaderns Digitals, núm. 53, pp. 1-21. Recuperado de http://www.quadernsdigitals.net/index. php?accionMenu=hemeroteca.VisualizaArticuloIU.visualizayarticulo_id=10493

Vassiliades, A. (2008, diciembre). Regulación social, gobernabilidad y políticas educativas entre la focalización y la heterodoxia: la propuesta del programa integral para la igualdad educativa. Educación, Lenguaje y Sociedad, vol. V, núm. 5, pp. 187-212. Recuperado de http://www.biblioteca.unlpam.edu.ar/ pubpdf/ieles/n05a10vassiliades.pdf

Velasco, A., García, E. y Linares, T. (2012). Estilo docente en profesores universitarios venezolanos, según los enfoques conductista, cognitivista y constructivista. Revista Intercontinental de Psicología y Educación, vol. 14, núm. 1, pp. 141-167. Recuperado de http://www.redalyc.org/pdf/802/80224034008.pdf

Zorrilla, M. y Barba, B. (2008). Reforma educativa en México, descentrailización y nuevos actores. Sinéctica, núm. 30, pp. 1-30. Recuperado de https://sinectica.iteso.mx/index.php/SINECTICA/article/view/189 